\title{
Effect of post-deformation annealing on the R-phase transformation temperatures in NiTi
} shape memory alloys

Xiebin Wang*, Bert Verlinden and Jan Van Humbeeck

Department of Materials Engineering, University of Leuven (KU Leuven), Kasteelpark Arenberg 44 bus 2450, Heverlee B3001, Belgium.

*Corresponding author: Tel.: +32 16 373549. Fax: +32 16321990.

E-mail address: xiebin.wang@mtm.kuleuven.be (X. Wang)

\begin{abstract}
In NiTi shape memory alloys, both the annihilation of dislocations and the formation of $\mathrm{Ni}_{4} \mathrm{Ti}_{3}$ precipitates may occur during post-deformation annealing. Different responses of the R-phase transformation temperatures to the annealing conditions have been reported. In order to find out the main factor(s) affecting the R-phase transformation temperatures during post-deformation annealing, a Ti-49.8 at.\% $\mathrm{Ni}$ and a $\mathrm{Ti}-50.8$ at.\% $\mathrm{Ni}$ alloy were subjected to various postdeformation annealing and thermal cycling treatments. The results show that the R-phase transformation temperatures are very stable in the Ti-49.8 at.\% $\mathrm{Ni}$ alloy, while a significant variation is observed in the $\mathrm{Ti}-50.8$ at.\% $\mathrm{Ni}$ alloy with respect to the annealing and thermal cycling conditions. These findings suggest that the R-phase transformation temperatures are not susceptible to the change of dislocation density and depends mainly on the $\mathrm{Ni}$ concentration of the matrix, which can be modified by the formation of $\mathrm{Ni}_{4} \mathrm{Ti}_{3}$ precipitates.
\end{abstract}

Keywords: A. shape-memory alloys; B. martensitic transformation, annealing; F. differential scanning calorimetry. 


\section{Introduction}

In near equiatomic NiTi alloys, the reversible martensitic transformation between the austenite phase (A) and the R-phase is attracting increasing interest for practical applications [1], due to its unique properties (e.g. narrow hysteresis [2,3], excellent functional fatigue resistance [4] and fast response to temperature changes [5,6]). With the presence of coherent $\mathrm{Ni}_{4} \mathrm{Ti}_{3}$ precipitates and/or dislocation networks, the R-phase can appear as an intermediate step before the formation of final B19' structured martensite (M) during cooling [7]. The coherent $\mathrm{Ni}_{4} \mathrm{Ti}_{3}$ precipitates and/or dislocation networks can be introduced by various thermomechanical treatments, such as aging treatment [3,8-10], thermal cycling [11,12] and post-deformation annealing [13-16]. The transformation temperature is a crucial factor for practical applications of the R-phase. It is therefore essential to investigate the evolution of the R-phase transformation temperatures (RTT) with respect to various thermomechanical treatments.

Coherent $\mathrm{Ni}_{4} \mathrm{Ti}_{3}$ precipitates can form in Ni-rich NiTi alloys during aging after a solution treatment, resulting in $\mathrm{Ni}$ depletion in the matrix [17,18] and the generation of strain fields around the precipitates [19]. Due to the small transformation strain $(\sim 1 \%)$ associated with $A \leftrightarrow R$ transformation [20], it is considered that the RTT in aged NiTi samples are not susceptible to the presence of the strain field, and depend mainly on the local Ni concentration in the matrix $[3,10]$. The R-phase transformation has been frequently observed in samples subjected to a thermally induced cyclic martensite transformation, due to the generation of dislocation networks [7,21]. With the accumulation of dislocations by increasing the thermal cycles, the volume fraction of the R-phase transformation gradually increases [22]. However, the RTT are rather stable with the increase in thermal cycles when the maximum cycling temperature $\left(\mathrm{T}_{\max }\right)$ is low, e.g. $\mathrm{T}_{\max }<423$ $\mathrm{K}[11,23]$. With an elevated $\mathrm{T}_{\max }($ e.g. $523 \mathrm{~K})$, an obvious increase in the RTT was observed in a 
Ni-rich NiTi alloy, due to the formation of $\mathrm{Ni}_{4} \mathrm{Ti}_{3}$ precipitates [12].

The effect of post-deformation annealing on the RTT is however complicated, as both the change of dislocation densities and the formation of $\mathrm{Ni}_{4} \mathrm{Ti}_{3}$ precipitates may occur. A decrease of the RTT with the increase in annealing temperatures has been frequently reported in Ni-rich NiTi alloys [13,14,24-26]. The annihilation of dislocations was considered as the main reason for the decrease of the RTT [24,27]. However, an increase of the RTT with the increase in annealing temperatures was also reported when annealing below 623 K [13,26]. Park et al. [27] suggested that the change of the RTT in Ni-rich NiTi alloys depends on the competition between the annihilation of dislocations and the formation of $\mathrm{Ni}_{4} \mathrm{Ti}_{3}$ precipitates. Todoroki and Tamura [25] found that the variation of the RTT with respect to annealing conditions becomes more pronounced with the increase in Ni content. On the other hand, the RTT are found to be very stable with respect to different annealing conditions in Ti-rich NiTi alloys [22,28]. As the annihilation of dislocations also occurs in Ti-rich NiTi alloys but not the formation of $\mathrm{Ni}_{4} \mathrm{Ti}_{3}$ precipitates [29], it seems that the change of dislocation densities during post-deformation annealing may have less effect on the RTT.

Post-deformation annealing treatment is an essential method to induce the R-phase transformation with a high transformation temperature in Ti-rich NiTi alloys, in which the formation of $\mathrm{Ni}_{4} \mathrm{Ti}_{3}$ precipitates is not occurring. Moreover, Miyazaki and Otsuka [29] reported that the reorientation of the R-phase, which is induced by the presence of dislocations networks, needs much higher stress than that of the R-phase induced by the presence of precipitates. This behavior yields interesting properties for the damping applications of the R-phase transformation. Therefore, it is important to reveal the main factor affecting the RTT during post-deformation 
annealing and thus to control the RTT.

In this study, a Ti-rich and a Ni-rich NiTi alloy were subjected to various annealing treatments. With increasing annealing temperature and time, the dislocations were gradually annihilated. In the Ni-rich NiTi alloys, the formation of $\mathrm{Ni}_{4} \mathrm{Ti}_{3}$ precipitates is expected during annealing [27,29], while the influence of precipitates can be excluded in the Ti-rich NiTi alloys [29]. Besides gradually annihilating dislocations by annealing, thermal cycling tests were employed in this study to gradually accumulate dislocations. The evolution of the RTT with respect to the various treatments is investigated.

\section{Materials and experimental procedures}

In this study, two cold-deformed NiTi alloys with different nominal compositions (Ti-49.8 at.\% $\mathrm{Ni}$ and Ti-50.8 at.\% Ni) were used. The Ti-49.8 at.\% Ni wire (diameter $7 \mathrm{~mm}$ ) and the Ti-50.8 at.\% $\mathrm{Ni}$ wire (diameter $2.7 \mathrm{~mm}$ ) were produced by room-temperature wire drawing with a final pass deformation of around $20 \%$ and $35 \%$, respectively. The as-received samples were first annealed at various temperatures between 473 and $873 \mathrm{~K}$ (with an interval of $50 \mathrm{~K}$ ) for 1 hour to investigate the effect of annealing temperature on the RTT. In order to study the influence of annealing time on the RTT, the as-received samples were annealed at the temperatures between 523 and $823 \mathrm{~K}$ (with an interval of $100 \mathrm{~K}$ ) for various durations from 1 to 48 hours. All the heat treatments were performed in argon atmosphere, followed by water quenching at room temperature. The transformation behavior was characterized by differential scanning calorimetry (DSC) in a TA Q2000 calorimeter between 123 and $423 \mathrm{~K}$ with a cooling/heating rate of $10 \mathrm{~K}$ $\min ^{-1}$. 
The solution treated samples (annealed at $1273 \mathrm{~K}$ for 2 hours) were used to perform the thermal cycling tests in the same DSC instrument with a constant cooling/heating rate of $10 \mathrm{~K} \mathrm{~min}^{-1}$. The transformation behavior of the solution treated samples is shown in Fig. 1. The thermal cycling tests $\left(25\right.$ cycles) were performed between a lowest temperature $\left(\mathrm{T}_{\min }\right)$ of $123 \mathrm{~K}$ and different $\mathrm{T}_{\max }$ of 423 and $523 \mathrm{~K}$, respectively. The samples were held at both $\mathrm{T}_{\min }$ and $\mathrm{T}_{\max }$ for 5 min during each thermal cycle.

\section{Results and discussion}

\subsection{Effect of annealing temperatures}

The transformation behavior of the as-received Ti-49.8 at.\% Ni alloy after annealing at different temperatures for 1 hour is shown in Fig. 2a-b. The R-phase transformation occurs when annealing below $873 \mathrm{~K}$, leading to a two-stage forward transformation $\mathrm{A} \rightarrow \mathrm{R} \rightarrow \mathrm{M}$, as shown in Fig. 2a. A one-stage reverse transformation $\mathrm{M} \rightarrow \mathrm{A}$ is observed in all samples upon heating, as shown in Fig. 2b. The R-phase transformation start $\left(R_{s}\right)$ and peak $\left(R_{p}\right)$ temperatures of the Ti49.8 at.\% $\mathrm{Ni}$ alloy during forward transformation as a function of annealing temperature is presented in Fig. 3. Both $R_{s}$ and $R_{p}$ are very stable with the increase in annealing temperatures. A small scatter of $R_{p}$ between 321 and $323 \mathrm{~K}$ with the increase in annealing temperature from 473 to $823 \mathrm{~K}$ is observed. This result gives a first indication that the recovery of the cold deformation sample (decrease of dislocation density) has minor influence on the RTT.

Fig. 2c-d shows the transformation behavior of the as-received Ti-50.8 at.\% Ni alloy after annealing at different temperatures for 1 hour. The forward transformation occurs in two stages from austenite to the R-phase and further to martensite in the samples annealed between 523 and $823 \mathrm{~K}$. A two-stage reverse transformation $\mathrm{M} \rightarrow \mathrm{R} \rightarrow \mathrm{A}$ is detected in the samples annealed 
between 523 and 723 K. Fig. 2c shows that the $A \rightarrow R$ transformation peak becomes sharper with the increase in annealing temperature. The reason for this phenomenon is not clear yet, and further investigations are needed. $\mathrm{R}_{\mathrm{s}}$ and $\mathrm{R}_{\mathrm{p}}$ of the Ti-50.8 at.\% $\mathrm{Ni}$ alloy is plotted as a function of annealing temperature in Fig. 3. $R_{s}$ and $R_{p}$ show a pronounced variation, in contrast with the results of the Ti-49.8 at.\% Ni alloy. $\mathrm{R}_{\mathrm{p}}$ increases with the increase in annealing temperature from 523 to $673 \mathrm{~K}$, while a decrease of $\mathrm{R}_{\mathrm{p}}$ is observed with a further increase in annealing temperature to $823 \mathrm{~K}$.

The density of dislocations gradually decreases with the increase in annealing temperature. Apart from the annihilation of dislocations, precipitation of the $\mathrm{Ni}_{4} \mathrm{Ti}_{3}$ phase is frequently observed in Ni-rich alloys at the temperature range of 473-873 K [6,10,29-32], but not in the Ti-rich alloys [29]. Therefore, by comparing the Ti-50.8 at.\% Ni alloy with the Ti-49.8 at.\% Ni alloy, the significant variation of $\mathrm{R}_{\mathrm{p}}$ with respect to annealing temperatures in Ti-50.8 at.\% Ni alloy must be due to the formation of $\mathrm{Ni}_{4} \mathrm{Ti}_{3}$ precipitates, which affect the Ni concentration of the matrix.

According to the equilibrium phase diagram between $\mathrm{Ni}_{4} \mathrm{Ti}_{3}$ precipitates and $\mathrm{B} 2$ matrix, the solid solubility of $\mathrm{Ni}$ in $\mathrm{B} 2$ matrix gradually increases with the increase in temperature [3]. The equilibrium is reached after annealing at high temperatures (723-823 K) for 1 hour, as reported in the samples subjected to aging after solution treatment [10]. Therefore, the Ni concentration in the matrix gradually increases with the increase in annealing temperatures. As a result, the RTT of Ti-50.8 at.\% Ni alloy gradually decrease with the increase in annealing temperature from 723 to $823 \mathrm{~K}$. However, the equilibrium cannot be reached after annealing at low temperatures (523$623 \mathrm{~K}$ ) for only 1 hour, as reported in the samples subjected to aging after solution treatment [10]. The precipitation kinetics is mainly driven by annealing temperatures. Therefore, the volume 
fraction of $\mathrm{Ni}_{4} \mathrm{Ti}_{3}$ precipitates gradually increases with the increase in annealing temperatures, leading to the increase in the Ni depletion in the matrix. As a result, the RTT of Ti-50.8 at.\% Ni alloy gradually increase with the increase in annealing temperature from 523 to $623 \mathrm{~K}$, as shown in Fig. 3. After annealing at $673 \mathrm{~K}$ for 1 hour, the $\mathrm{Ni}$ depletion in the matrix reaches the maximum by the formation of $\mathrm{Ni}_{4} \mathrm{Ti}_{3}$ precipitates, resulting in the highest $\mathrm{RTT}$.

\subsection{Effect of annealing time}

Fig. 4 shows the forward transformation behavior of the Ti-49.8 at.\% Ni alloy after annealing at different temperatures for 1 to 48 hours. Two-stage transformation $\mathrm{A} \rightarrow \mathrm{R} \rightarrow \mathrm{M}$ is observed in the samples annealed at 523 to $723 \mathrm{~K}$ for different times, as shown in Fig. 4a-c. The $\mathrm{A} \rightarrow \mathrm{R}$ and $\mathrm{R} \rightarrow \mathrm{M}$ transformation peaks overlap with each other when annealing at $823 \mathrm{~K}$ for 1 hour, as shown in Fig. 4d. Fig. 5 shows the variation of $\mathrm{R}_{\mathrm{p}}$ of the Ti-49.8 at.\% Ni alloy with respect to annealing time at different annealing temperatures. $\mathrm{R}_{\mathrm{p}}$ lies in a narrow temperature range between 321 and $324 \mathrm{~K}$. As the dislocation density gradually decreases with the increase in annealing time or temperature, the small scatter of $\mathrm{R}_{\mathrm{p}}$ indicates that the RTT are not susceptible to the change of dislocation densities.

The forward transformation behavior of the Ti-50.8 at.\% Ni alloy after annealing at different temperatures for 1 to 48 hours is shown in Fig. 6. The R-phase transformation is observed in the samples annealed at 523 to $723 \mathrm{~K}$ for different times, as presented in Fig. 6a-c. Two-stage transformation $\mathrm{A} \rightarrow \mathrm{R} \rightarrow \mathrm{M}$ is observed in the sample annealed at $823 \mathrm{~K}$ for 1 hour, while with the increase of annealing time to 4 and 8 hours, multi-stage transformation is detected, as shown in Fig. 6d. The severe decrease of dislocations and heterogeneous distribution of the $\mathrm{Ni}_{4} \mathrm{Ti}_{3}$ precipitates are considered as the main reason for the appearance of the multi-stage 
transformation, as reported in aged samples [33,34]. Nevertheless, further investigation is required to explain this phenomenon.

Fig. 7 shows the variation of $\mathrm{R}_{\mathrm{p}}$ of the Ti-50.8 at.\% $\mathrm{Ni}$ alloy with respect to annealing time at different annealing temperatures. $\mathrm{R}_{\mathrm{p}}$ continuously increases from $273 \mathrm{~K}$ to $308 \mathrm{~K}$ with increasing annealing time from 1 to 48 hours when annealing at $523 \mathrm{~K}$. The increase of $\mathrm{R}_{\mathrm{p}}$ is attributed to the continuous Ni depletion in the matrix, which is caused by the increase in the volume fraction of $\mathrm{Ni}_{4} \mathrm{Ti}_{3}$ precipitates with increasing annealing time. When annealing at $623 \mathrm{~K}, \mathrm{R}_{\mathrm{p}}$ first increases from 306 to $317 \mathrm{~K}$ with increasing annealing time from 1 to 8 hours. $\mathrm{R}_{\mathrm{p}}$ remains stable with further increasing annealing time to 24 and 48 hours, as shown in Fig. 7. The increase of $R_{p}$ is also due to the increasing volume fraction of $\mathrm{Ni}_{4} \mathrm{Ti}_{3}$ precipitates with increasing annealing time. The equilibrium condition between the $\mathrm{B} 2$ matrix and $\mathrm{Ni}_{4} \mathrm{Ti}_{3}$ precipitate can be reached after annealing for 24 hours. The Ni concentration maintains the equilibrium value, thus $R_{p}$ remains stable with increasing annealing time from 24 to 48 hours.

$R_{p}$ varies between 303 and $308 \mathrm{~K}$ with increasing annealing time from 1 to 48 hours when annealing at $723 \mathrm{~K}$. This insensitivity of $R_{p}$ with respect to the annealing time is due to the fact that the equilibrium condition between $\mathrm{Ni}_{4} \mathrm{Ti}_{3}$ precipitates and the $\mathrm{B} 2$ matrix is already achieved after annealing at $723 \mathrm{~K}$ for 1 hour. Xue et al. [10] reported the same phenomenon in the samples subjected to aging after solution treatment. The Ni concentration of the matrix maintains the equilibrium value, thus $R_{p}$ remains stable with increasing annealing time from 1 to 48 hours. $R_{p}$ with a value of $260 \mathrm{~K}$ is observed in the sample annealed at $823 \mathrm{~K}$ for 1 hour. This is due to the high solubility of $\mathrm{Ni}$ in the matrix at the temperature of $823 \mathrm{~K}$, as indicated by the equilibrium phase diagram between $\mathrm{Ni}_{4} \mathrm{Ti}_{3}$ and $\mathrm{B} 2$ matrix [3]. 


\subsection{Effect of thermal cycling}

Dislocations can be gradually accumulated with the increase in the number of thermally induced martensite transformation cycles $[11,35]$. Moreover, with elevated maximum cycling temperature $\left(\mathrm{T}_{\max }\right), \mathrm{Ni}_{4} \mathrm{Ti}_{3}$ precipitates can be introduced into the Ni-rich alloys during thermal cycling [12]. As shown in Fig. 8, the Ti-49.8 at.\% Ni and Ti-50.8 at.\% Ni alloys are subjected to thermal cycling tests with different $T_{\max }$, in order to separate the influence of the change in dislocation densities and the formation of $\mathrm{Ni}_{4} \mathrm{Ti}_{3}$ precipitates on the $\mathrm{RTT}$.

Fig. 8a-b shows the evolution of the transformation behavior of the Ti-49.8 at.\% Ni alloy during thermal cycling between $\mathrm{T}_{\min }$ of $123 \mathrm{~K}$ and different $\mathrm{T}_{\max }$ of 423 and $523 \mathrm{~K}$, respectively. Only the DSC data between 150 and $400 \mathrm{~K}$ is presented, as the heat flow remains constant outside of this temperature range. The samples were isothermally held at both $T_{\min }$ and $T_{\max }$ for $5 \mathrm{~min}$ during each cycle. As shown in Fig. $8 \mathrm{a}, \mathrm{A} \rightarrow \mathrm{R}$ transformation is observed in the $7^{\text {th }}$ cycle for the test with $\mathrm{T}_{\max }$ of $423 \mathrm{~K}$. With a higher $\mathrm{T}_{\max }$ of $523 \mathrm{~K}, \mathrm{~A} \rightarrow \mathrm{R}$ transformation can be detected from the $12^{\text {th }}$ cycle on, as shown in Fig. $8 \mathrm{~b}$. This is due to the slight annihilation of dislocations at the temperature of $523 \mathrm{~K}$, which delays the accumulation of dislocations during thermal cycling. In both samples, the B19' martensite transformation is gradually suppressed with the increase in thermal cycles.

The transformation behavior of the Ti-50.8 at.\% Ni alloy during thermal cycling between $\mathrm{T}_{\min }$ of $123 \mathrm{~K}$ and different $\mathrm{T}_{\max }$ of 423 and $523 \mathrm{~K}$ are respectively shown in Fig. 8c and 8d. A distinguishable R-phase transformation peak is observed in the $17^{\text {th }}$ cycle for the test with $\mathrm{T}_{\max }$ of $423 \mathrm{~K}$, as shown in Fig. 8c. Comparing with the Ti-49.8 at.\% Ni alloy (Fig. 8a), the occurrence of the R-phase transformation is much later in the Ti-50.8 at.\% $\mathrm{Ni}$ alloy. This is due to the fact that 
the excess solute $\mathrm{Ni}$ atoms hinder the accumulation of dislocations in the Ti-50.8 at.\% Ni alloy [11,36]. The R-phase transformation occurs much earlier in the Ti-50.8 at.\% Ni alloy when subjected to the thermal cycling with $\mathrm{T}_{\max }$ of $523 \mathrm{~K}$, despite of the slight annihilation of dislocations. Moreover, the suppression of martensite transformation is pronounced in the sample subjected to thermal cycling with $\mathrm{T}_{\max }$ of $523 \mathrm{~K}$.

Fig. 9a shows the evolution of $\mathrm{R}_{\mathrm{p}}$ and $\mathrm{M}_{\mathrm{p}}$ of the Ti-49.8 at.\% $\mathrm{Ni}$ alloy during thermal cycling tests. $\mathrm{R}_{\mathrm{p}}$ of the Ti-49.8 at.\% $\mathrm{Ni}$ alloy is constant during thermal cycling with $\mathrm{T}_{\max }$ of both 423 and $523 \mathrm{~K} . \mathrm{R}_{\mathrm{p}}$ maintains at $317 \mathrm{~K}$ during the thermal cycling tests with $\mathrm{T}_{\max }$ of $423 \mathrm{~K}$, while $\mathrm{R}_{\mathrm{p}}$ becomes $320 \mathrm{~K}$ for the test with $\mathrm{T}_{\max }$ of $523 \mathrm{~K}$. The difference of $\mathrm{R}_{\mathrm{p}}$ between the test with $\mathrm{T}_{\max }$ of 423 and $523 \mathrm{~K}$ is attributed to the slight composition variation between the samples used in the tests. With the increase in the number of thermal cycles, $\mathbf{M}_{\mathrm{p}}$ gradually decreases for both samples, due to the accumulation of dislocations [11], which act as the obstacles for martensite transformation $[3,7]$. Due to the slight annihilation of dislocations with a higher $\mathrm{T}_{\max }$ of $523 \mathrm{~K}$, the accumulation of dislocations is delayed. As a result, martensite transformation is less suppressed in the sample subjected to the thermal cycling test with $\mathrm{T}_{\max }$ of $523 \mathrm{~K}$.

The evolution of $\mathrm{R}_{\mathrm{p}}$ and $\mathrm{M}_{\mathrm{p}}$ of the Ti-50.8 at.\% Ni alloy during thermal cycling tests is shown in Fig. 9b. With $\mathrm{T}_{\max }$ of $423 \mathrm{~K}$, the thermal cycling hardly affects the R-phase transformation temperature, and $\mathrm{R}_{\mathrm{p}}$ maintains at around $234 \mathrm{~K}$. As the temperature is low, almost no $\mathrm{Ni}_{4} \mathrm{Ti}_{3}$ precipitates are expected during the thermal cycling test with $\mathrm{T}_{\max }$ of $423 \mathrm{~K}$. With the increase of $\mathrm{T}_{\max }$ to $523 \mathrm{~K}, \mathrm{R}_{\mathrm{p}}$ gradually increases from 242 to $280 \mathrm{~K}$ with increasing number of thermal cycles from 6 to 25 . The increase of the RTT is attributed to the continuous Ni depletion by increasing the volume fraction of $\mathrm{Ni}_{4} \mathrm{Ti}_{3}$ precipitates with increasing number of thermal cycles 
[12]. As shown in Fig. 9b, a pronounced decrease of $\mathrm{M}_{\mathrm{p}}$ from 232 to $177 \mathrm{~K}$ is observed in the Ti50.8 at.\% $\mathrm{Ni}$ alloy when subjected to thermal cycling with $\mathrm{T}_{\max }$ of $523 \mathrm{~K}$, despite of the slight annihilation of dislocations. This is attributed to the formation of coherent $\mathrm{Ni}_{4} \mathrm{Ti}_{3}$ nanoprecipitates during the thermal cycling with $\mathrm{T}_{\max }$ of $523 \mathrm{~K}$ [12], which suppresses the martensite transformation $[6,7,37]$.

The above findings show that the evolution of the RTT during thermal cycling depends on the composition of the samples as well as $\mathrm{T}_{\max }$. When no $\mathrm{Ni}_{4} \mathrm{Ti}_{3}$ precipitates are introduced (e.g., in the Ti-49.8 at.\% Ni alloy or in the Ti-50.8 at.\% Ni alloy subjected to thermal cycling with $\mathrm{T}_{\max }$ of $423 \mathrm{~K}$ ), the RTT are stable even though the dislocations are gradually accumulated with an increase in the number of thermal cycles. Due to the gradual Ni depletion in the matrix, which is caused by the formation of $\mathrm{Ni}_{4} \mathrm{Ti}_{3}$ precipitates, the increase in the RTT is observed in $\mathrm{Ti}-50.8$ at. $\%$ Ni alloy during thermal cycling with an elevated $\mathrm{T}_{\max }$ of $523 \mathrm{~K}$.

\section{Conclusions}

In this study, cold deformed $\mathrm{Ti}-49.8$ at.\% $\mathrm{Ni}$ and $\mathrm{Ti}-50.8$ at.\% $\mathrm{Ni}$ alloys were subjected to postdeformation annealing and thermal cycling treatments under various conditions. The evolution of the R-phase transformation temperatures has been investigated. The results observed in this study has led us to conclude that the R-phase transformation temperature is not susceptible to the density of dislocations and depends mainly on the Ni concentration of the matrix, which can be modified by the presence of $\mathrm{Ni}_{4} \mathrm{Ti}_{3}$ precipitates.

\section{Acknowledgement}

This work was supported by the Research Foundation Flanders (FWO) under Grant No. 
G.0576.09N. X. Wang wishes to thank the China Scholarship Council (CSC) for financial support. The assistance from D. Winant, L. Chen and P. Crabbé is highly appreciated.

\section{References:}

[1] Wang X, Verlinden B, Van Humbeeck J. R-phase transformation in NiTi alloys. Mater Sci Technol 2014;30:1517-29.

[2] Miyazaki S, Otsuka K. Mechanical behavior associated with the premartensitic rhombohedral-phase transition in a $\mathrm{Ti}_{50} \mathrm{Ni}_{47} \mathrm{Fe}_{3}$ alloy. Philos Mag A 1984;50:393-408.

[3] Otsuka K, Ren X. Physical metallurgy of Ti-Ni-based shape memory alloys. Prog Mater Sci 2005;50:511-678.

[4] Tobushi H, Yamada S, Hachisuka T, Ikai A, Tanaka K. Thermomechanical properties due to martensitic and R-phase transformations of TiNi shape memory alloy subjected to cyclic loadings. Smart Mater Struct 1996;5:788-95.

[5] Šittner P, Landa M, Lukáš P, Novák V. R-phase transformation phenomena in thermomechanically loaded NiTi polycrystals. Mech Mater 2006;38:475-92.

[6] Wang X, Li K, Schryvers D, Verlinden B, Van Humbeeck J. R-phase transition and related mechanical properties controlled by low-temperature aging treatment in a Ti-50.8 at.\% Ni thin wire. Scripta Mater 2014;72-73:21-4.

[7] Ren X, Miura N, Zhang J, Otsuka K, Tanaka K, Koiwa M, et al. A comparative study of elastic constants of Ti-Ni-based alloys prior to martensitic transformation. Mater Sci Eng A 2001;312:196-206.

[8] Wang X, Li C, Verlinden B, Van Humbeeck J. Effect of grain size on aging microstructure as reflected in the transformation behavior of a low-temperature aged Ti-50.8 at.\% Ni alloy. Scripta Mater 2013;69:545-8. 
[9] Jiang F, Li L, Zheng Y, Yang H, Liu Y. Cyclic aging of Ti-50.8 at.\% Ni alloy. Intermetallics $2008 ; 16: 394-8$.

[10] Xue D, Zhou Y, Ren X. The effect of aging on the B2-R transformation behaviors in Ti51 at $\% \mathrm{Ni}$ alloy. Intermetallics 2011;19:1752-8.

[11] Miyazaki S, Igo Y, Otsuka K. Effect of thermal cycling on the transformation temperatures of Ti-Ni alloys. Acta Metall 1986;34:2045-51.

[12] Wagner MF-X, Dey SR, Gugel H, Frenzel J, Somsen Ch, Eggeler G. Effect of lowtemperature precipitation on the transformation characteristics of Ni-rich NiTi shape memory alloys during thermal cycling. Intermetallics 2010;18:1172-9.

[13] Huang X, Liu Y. Effect of annealing on the transformation behavior and superelasticity of NiTi shape memory alloy. Scripta Mater 2001;45:153-160.

[14] Mahmud AS, Yang H, Tee S, Rio G, Liu Y. Effect of annealing on deformation-induced martensite stabilization of NiTi. Intermetallics 2008;16:209-14.

[15] Srivastava AK, Schryvers D, Van Humbeeck J. Grain growth and precipitation in an annealed cold-rolled $\mathrm{Ni}_{50.2} \mathrm{Ti}_{49.8}$ alloy. Intermetallics 2007;15:1538-47.

[16] Jiang S, Zhang Y, Zhao L, Zheng Y. Influence of annealing on NiTi shape memory alloy subjected to severe plastic deformation. Intermetallics 2013;32:344-51.

[17] Zarinejad M, Liu Y, Tong Y. Transformation temperature changes due to second phase precipitation in NiTi-based shape memory alloys. Intermetallics 2009;17:914-9.

[18] Schryvers D, Tirry W, Yang ZQ. Measuring strain field and concentration gradients around $\mathrm{Ni}_{4} \mathrm{Ti}_{3}$ precipitates. Mater Sci Eng A 2006;438-440:485-8.

[19] Tirry W, Schryvers D. Linking a completely three-dimensional nanostrain to a structural transformation eigenstrain. Nat Mater 2009;8:752-7.

[20] Miyazaki S, Kimura S, Otsuka K. Shape-memory effect and pseudoelasticity associated with 
the R-phase transition in Ti-50.5 at.\% Ni single crystals. Philos Mag A 1988;57:467-78.

[21] Zhang J, Somsen C, Simon T, Ding X, Hou S, Ren S, et al. Leaf-like dislocation substructures and the decrease of martensitic start temperatures: A new explanation for functional fatigue during thermally induced martensitic transformations in coarse-grained Ni-rich Ti-Ni shape memory alloys. Acta Mater 2012;60:1999-2006.

[22] Uchil J, Ganesh Kumara K, Mahesh KK. Effect of thermal cycling on R-phase stability in a NiTi shape memory alloy. Mater Sci Eng A 2002;332:25-8.

[23] McCormick PG, Liu Y. Thermodynamic analysis of the martensitic transformation in NiTiII. Effect of transformation cycling. Acta Metall Mater 1994;42:2407-13.

[24] Wang ZG, Zu XT, Feng XD, Zhu S, Zhou JM, Wang LM. Annealing-induced evolution of transformation characteristics in TiNi shape memory alloys. Physica B 2004;353:9-14.

[25] Todoroki T, Tamura H. Effect of heat treatment after cold working on the phase transformation in TiNi alloy. Trans Japan Inst Met 1987;28:83-94.

[26] Matsumoto $\mathrm{H}$. Transformation behavior of NiTi in relation to thermal cycling and deformation. Physica B 1993;190:115-20.

[27] Park SH, Lee JH, Nam TH, Lee YJ, Inoue K, Lee SW, et al. Effect of proportional control treatment on transformation behavior of Ti-50.9 at.\% Ni shape memory alloys. J Alloy Compd 2013;577S:S168-74.

[28] Khelfaoui F, Guénin G. Influence of the recovery and recrystallization processes on the martensitic transformation of cold worked equiatomic Ti-Ni alloy. Mater Sci Eng A 2003;355:292-8.

[29] Miyazaki S, Otsuka K. Deformation and transition behavior associated with the R-phase in Ti-Ni alloys. Metall Trans A 1986;17:53-63.

[30] Zhou Y, Zhang J, Fang G, Ding X, Sun J, Ren X, et al. Origin of 2-stage R-phase 
transformation in low-temperature aged Ni-rich Ti-Ni alloys. Acta Mater 2005;53:5365-77.

[31] Kim JI, Liu Y, Miyazaki S. Aging-induced two-stage R-phase transformation in Ti50.9at.\%Ni. Acta Mater 2004;52:487-99.

[32] Khalil-Allafi J, Eggeler G, Dlouhy A, Schmahl WW, Somsen Ch. On the influence of heterogeneous precipitation on martensitic transformations in a Ni-rich NiTi shape memory alloy. Mater Sci Eng A 2004;378:148-51.

[33] Khalil-Allafi J, Dlouhy A, Eggeler G. Ni4Ti3-precipitation during aging of NiTi shape memory alloys and its influence on martensitic phase transformations. Acta Mater 2002;50:425574.

[34] Fan G, Chen W, Yang S, Zhu J, Ren X, Otsuka K. Origin of abnormal multi-stage martensitic transformation behavior in aged Ni-rich Ti-Ni shape memory alloys. Acta Mater 2004;52:4351-62.

[35] Sandrock GD, Perkins AJ, Hehemann RF. The premartensitic instability in near-equiatomic TiNi. Metall Trans 1971;2:2769-81.

[36] Liu T, Zheng Y, Cui L. Influence of partial cycling on the transformation mass of NiTi alloys. Mater Lett 2013;112:121-3.

[37] Wang X, Kustov S, Li K, Schryvers D, Verlinden B, Van Humbeeck J. Effect of nanoprecipitates on the transformation behavior and functional properties of a $\mathrm{Ti}-50.8$ at. $\% \mathrm{Ni}$ alloy with micron-sized grains. Acta Mater 2015;82:224-33. 


\section{Figures:}

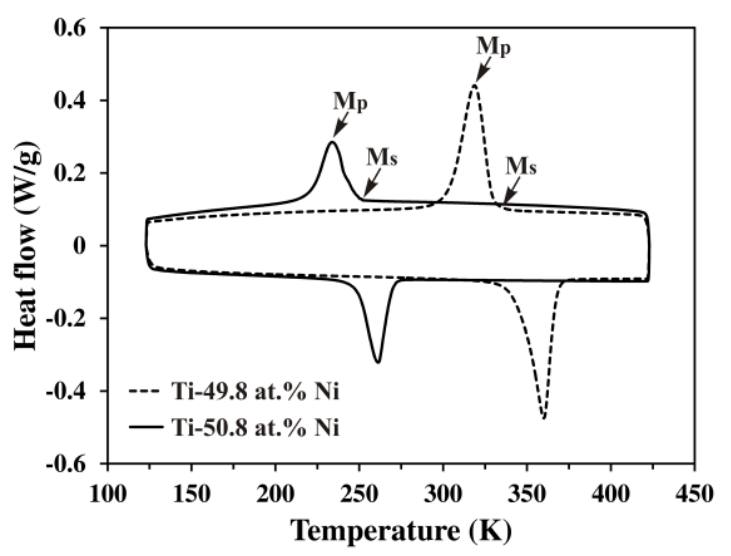

Fig. 1. Transformation behavior of the Ti-49.8 at.\% Ni and Ti-50.8 at.\% Ni alloy after annealing at $1273 \mathrm{~K}$ for 2 hours. 

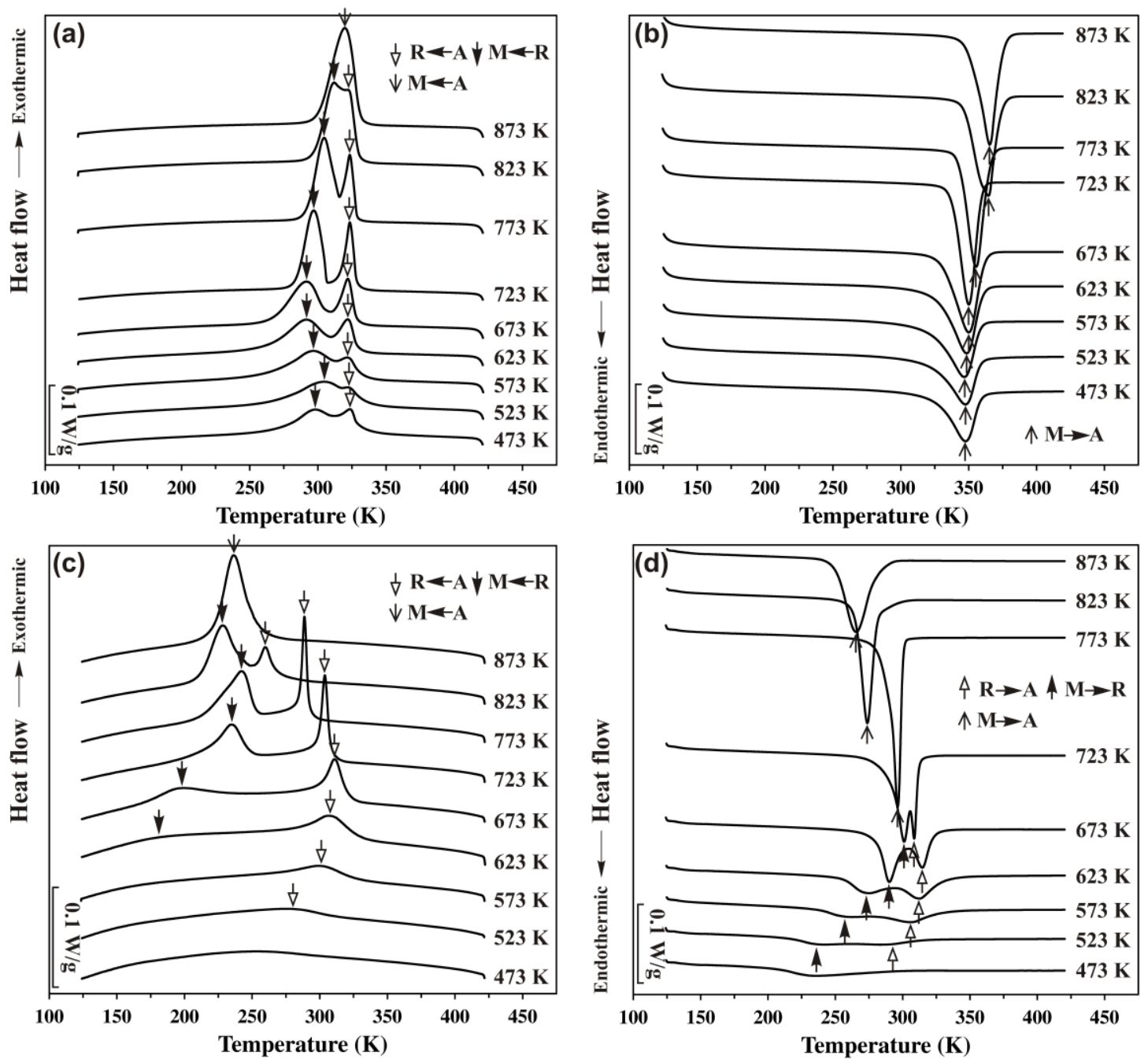

Fig. 2. Transformation behavior of the as-received Ti-49.8 at.\% $\mathrm{Ni}$ and Ti-50.8 at.\% $\mathrm{Ni}$ alloy after annealing at different temperatures for 1 hour. (a) Forward and (b) reverse transformation of the Ti-49.8 at.\% Ni alloy; (c) forward and (d) reverse transformation of the Ti-50.8 at.\% Ni alloy. 


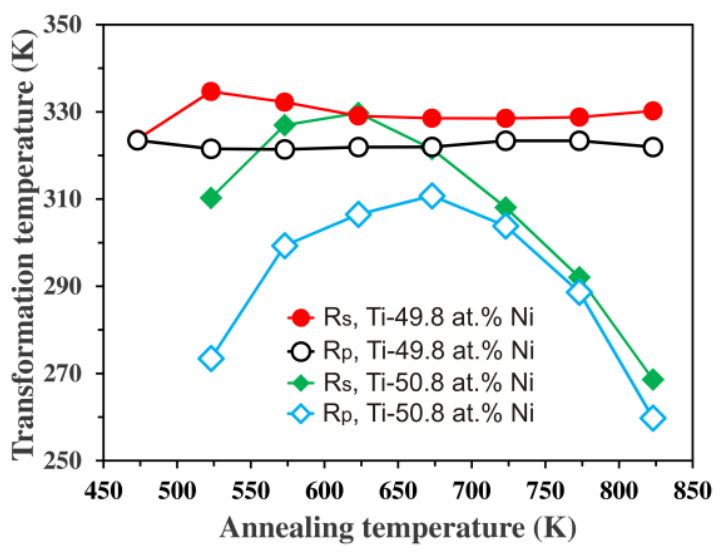

Fig. 3. The evolution of the R-phase transformation start $\left(R_{s}\right)$ and peak $\left(R_{p}\right)$ temperature of the Ti-49.8 at.\% $\mathrm{Ni}$ and $\mathrm{Ti}-50.8$ at.\% Ni alloy with respect to annealing temperature. 

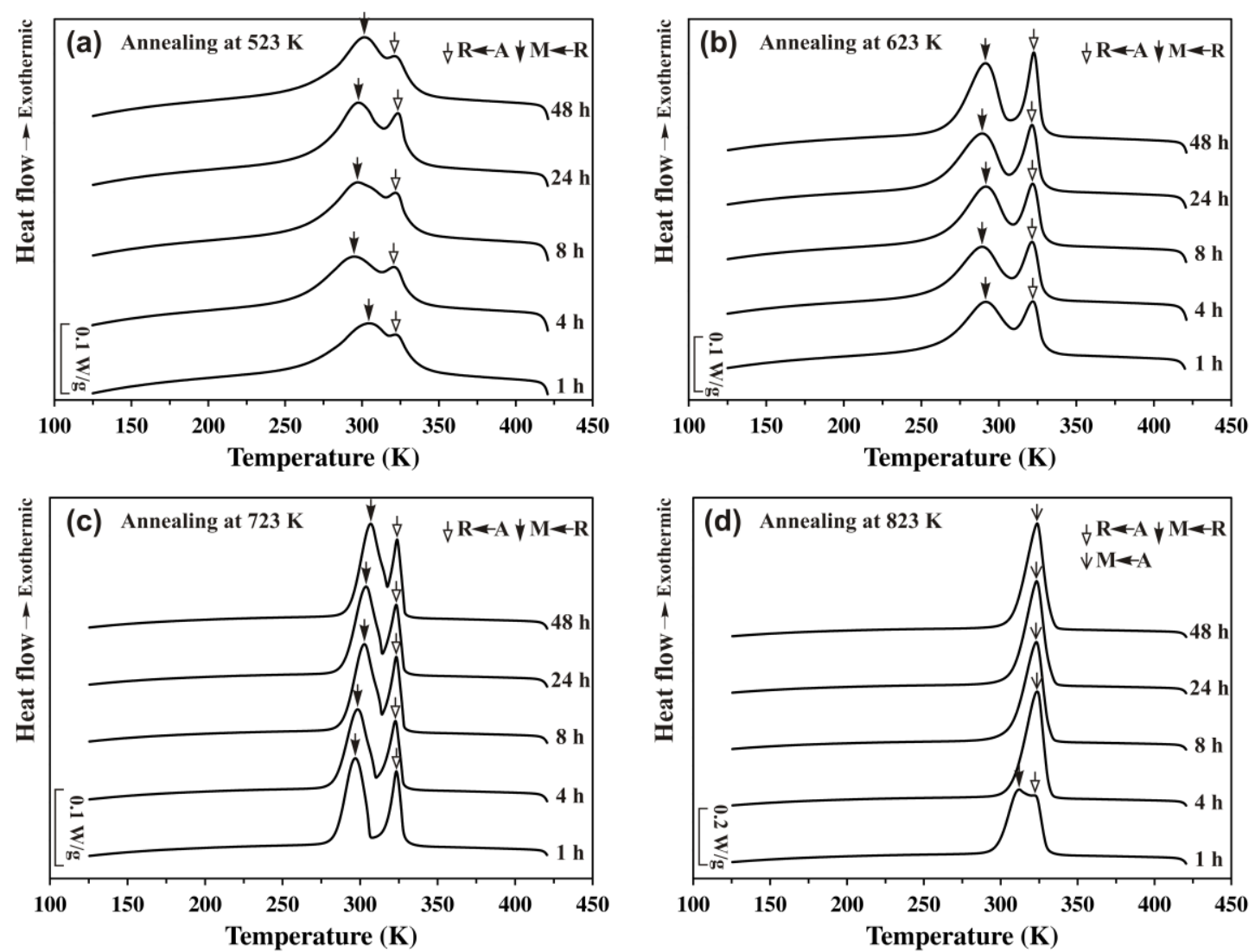

Fig. 4. Transformation behavior of the Ti-49.8 at.\% Ni alloy after annealing at (a) $523 \mathrm{~K}$; (b) 623 $\mathrm{K}$; (c) $723 \mathrm{~K}$ and (d) $823 \mathrm{~K}$ for different durations. 


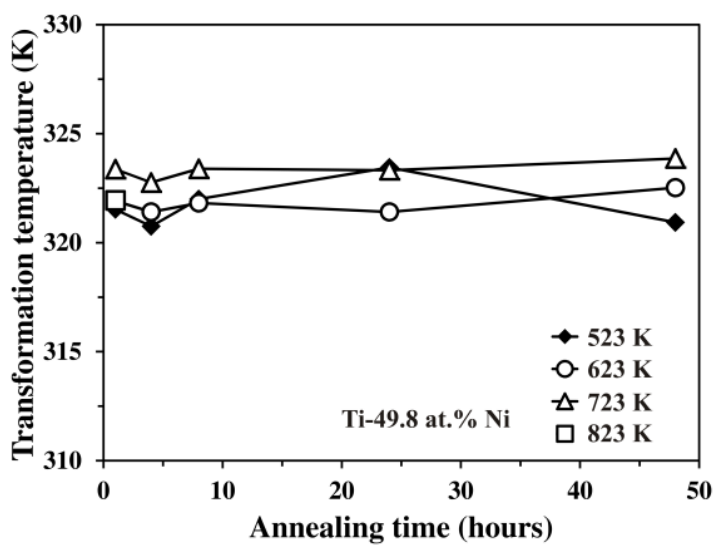

Fig. 5. The R-phase transformation peak temperature $\left(\mathrm{R}_{\mathrm{p}}\right)$ of the Ti-49.8 at.\% Ni alloy as a function of annealing time when annealed at different temperatures. 

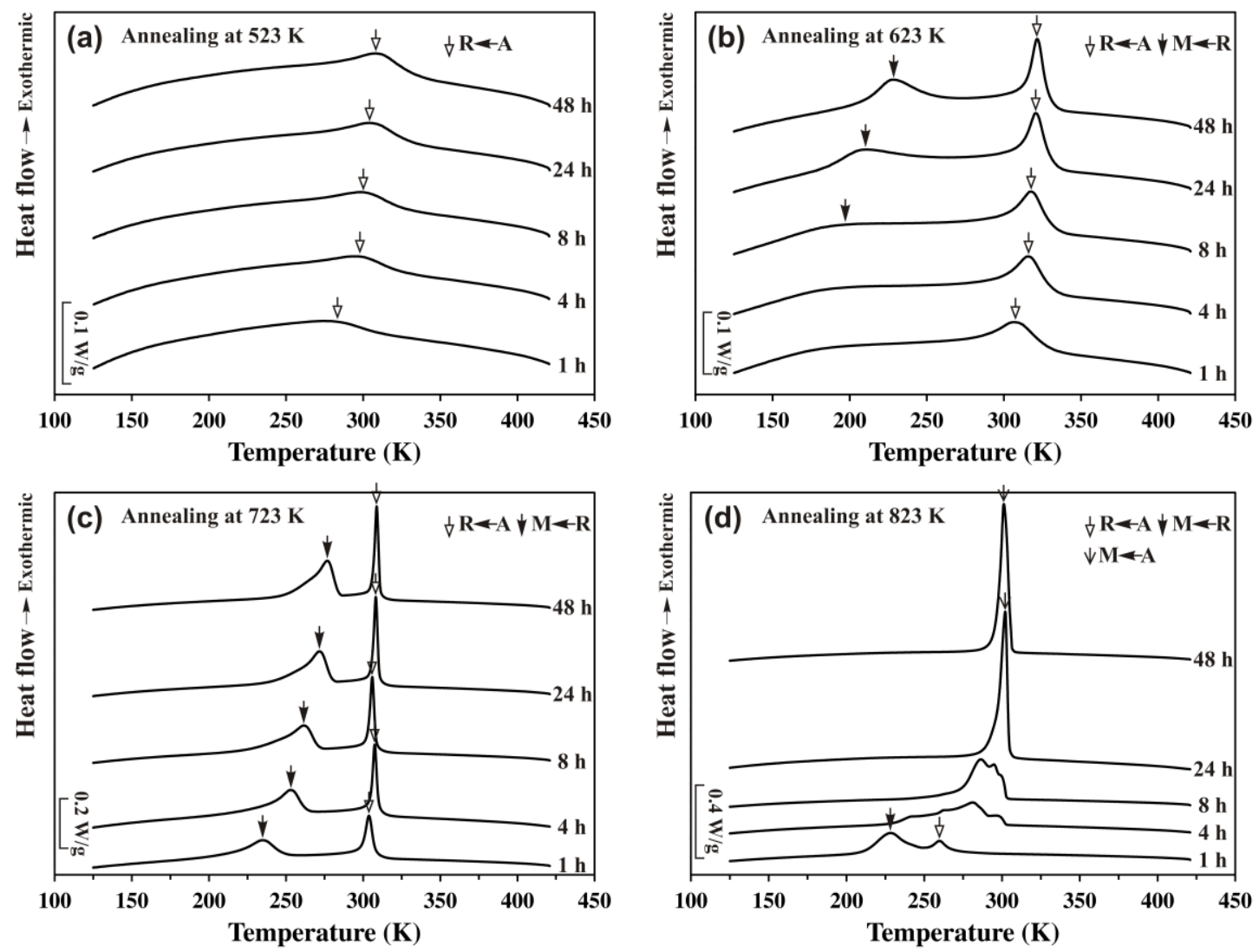

Fig. 6. Transformation behavior of the Ti-50.8 at.\% Ni alloy after annealing at (a) $523 \mathrm{~K}$; (b) 623 $\mathrm{K}$; (c) $723 \mathrm{~K}$ and (d) $823 \mathrm{~K}$ for different durations. 


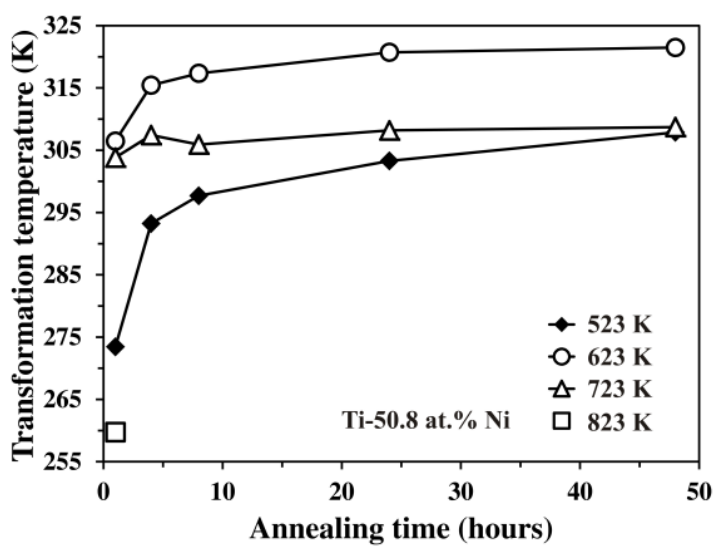

Fig. 7. The R-phase transformation peak temperature $\left(\mathrm{R}_{\mathrm{p}}\right)$ of the Ti-50.8 at.\% Ni alloy as a function of annealing time when annealed at different temperatures. 

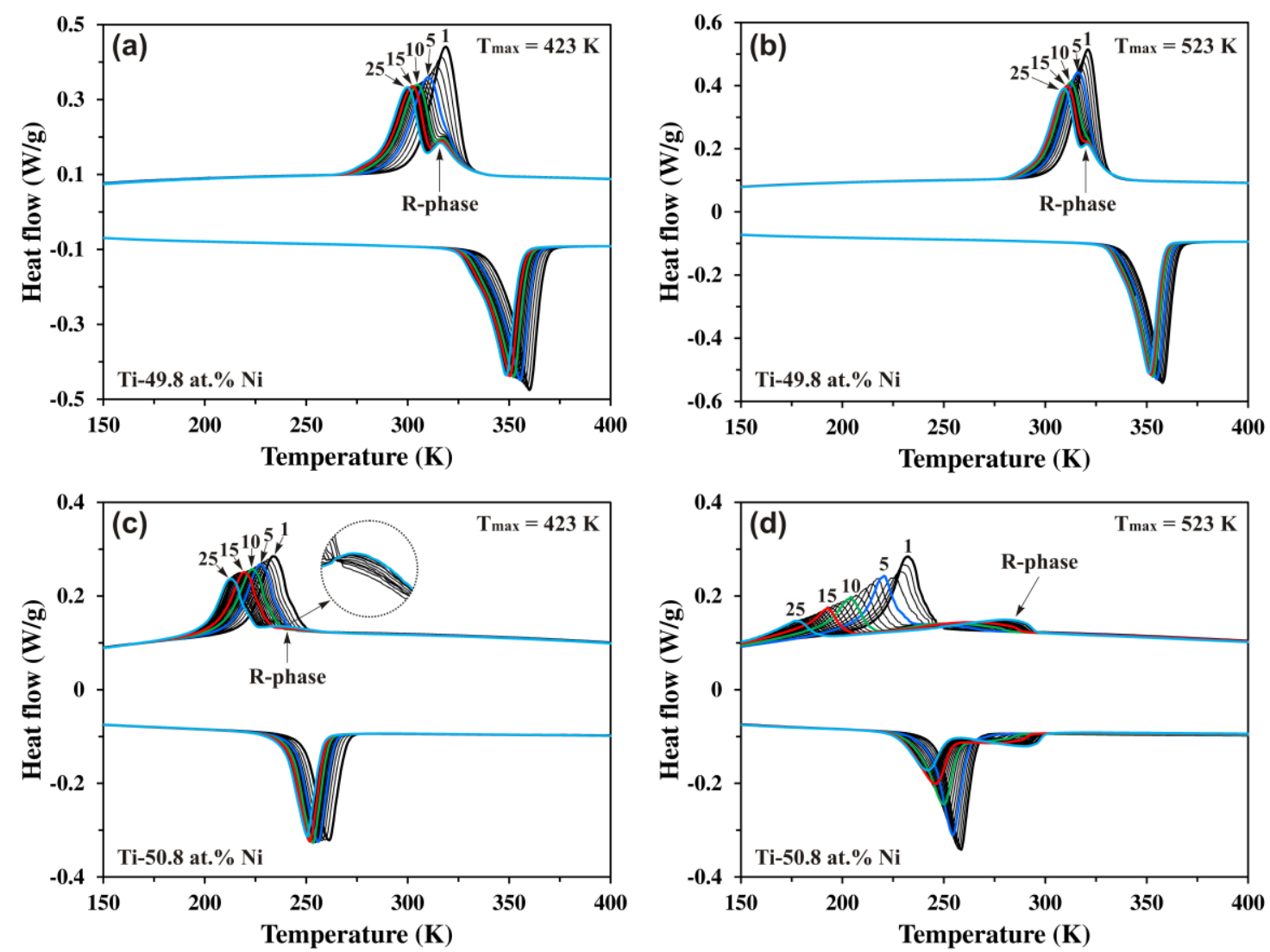

Fig. 8. Transformation behavior during thermal cycling between $123 \mathrm{~K}$ and different maximum temperatures ( $\mathrm{T}_{\max }$ ): (a) Ti-49.8 at.\% Ni alloy with $\mathrm{T}_{\max }$ of $423 \mathrm{~K}$; (b) Ti-49.8 at.\% Ni alloy with $\mathrm{T}_{\max }$ of $523 \mathrm{~K}$; (c) Ti-50.8 at.\% Ni alloy with $\mathrm{T}_{\max }$ of $423 \mathrm{~K}$; and (d) Ti-50.8 at.\% Ni alloy with $\mathrm{T}_{\max }$ of $523 \mathrm{~K}$. The samples were annealing at $1273 \mathrm{~K}$ for 2 hours before thermal cycling tests. 

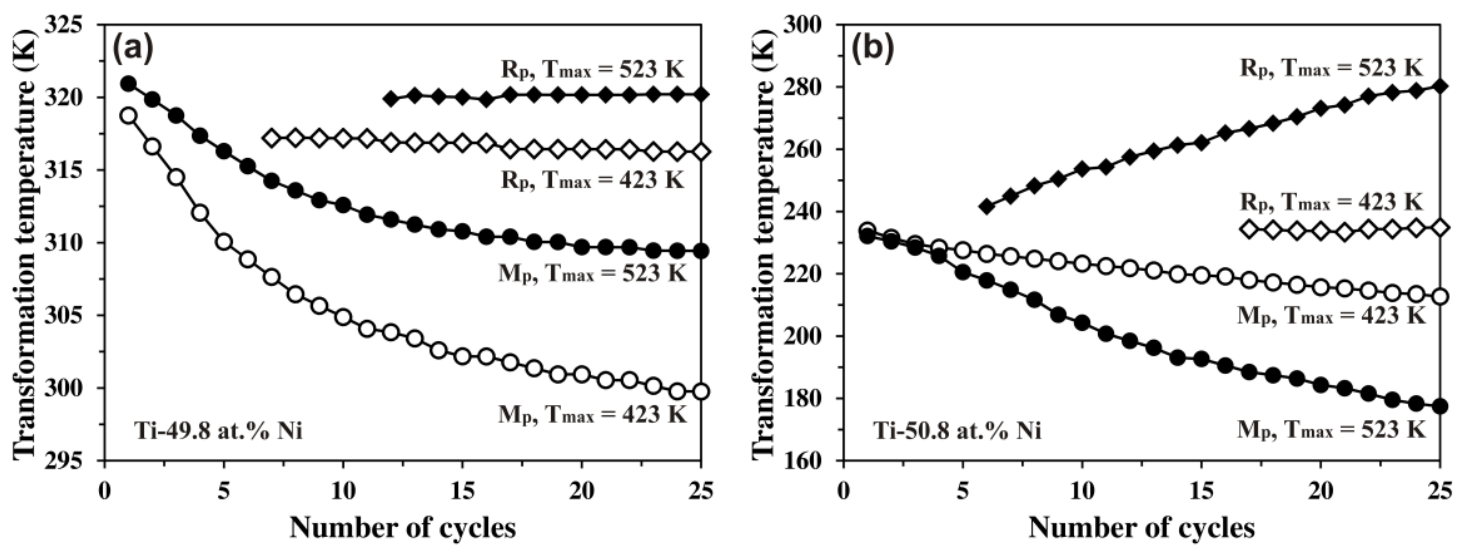

Fig. 9. Evolution of the peak transformation temperature of the R-phase $\left(R_{p}\right)$ and martensite $\left(M_{p}\right)$ transformation during thermal cycling with different $\mathrm{T}_{\max }$ : (a) Ti-49.8 at.\% $\mathrm{Ni}$ alloy and (b) Ti50.8 at.\% Ni alloy. 